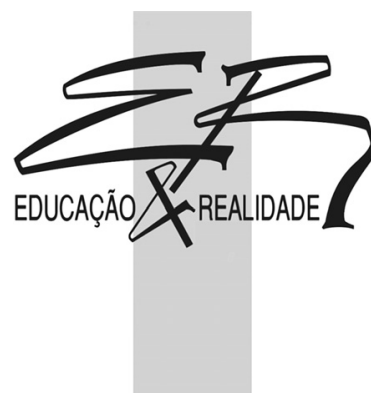

\title{
Trabalho e Formação
}

Marcio Pochmann

RESUMO - Trabalho e Formação ${ }^{1}$. A emergência de novas formas de trabalho, associada ao aumento da expectativa de vida da população, conecta-se com a perspectiva de alteração na formação educacional. Dentre outras características, a educação deixa de centrar-se nas fases precoces da vida para ser algo necessário ao longo da vida. Nessa transformação, o entendimento entre os atores sociais é condição necessária para a maior eficiência alocativa dos meios de produção. Da mesma forma, apresenta-se a possibilidade de compartilhamento dos novos ganhos de produtividade com patamar de civilidade superior ao do século 20. Formas de produção e de organização do trabalho sustentáveis requerem uma base recorrente de educação e formação profissional.

Palavras-chave: Trabalho. Formação para o Trabalho. Formação Profissional.

ABSTRACT - Labor and Training. The emergence of new forms of work, associated with the increase in the populations' life expectancy, connects with the perspective of changes in educational training. Among other characteristics, education ceases to center solely in the early phases of life to be lifelong. In this transformation, the understanding among social actors is a necessary condition to a better efficient allocation of means of production. By the same token, the possibility presents of sharing new gains of productivity with a higher threshold of civility than that of the twentieth century. Sustainable forms of production and of work organization require a basis of professional education and training.

Keywords: Work. Work Training. Professional Training.

Educ. Real., Porto Alegre, v. 37, n. 2, p. 491-508, maio/ago. 2012.

Disponivel em: <http://www.ufrgs.br/edu_realidade> 


\section{Introdução}

O funcionamento do mercado de trabalho sofre importante mutação desde o final do século 20. Com isso, o sistema de formação e qualificação profissional vem passando por revisões não desprezíveis em grande parte dos países, não obstante as diferenças consideráveis, cujos resultados impõem novos entendimentos entre o Estado, empresas e trabalhadores.

Várias são as razões responsáveis pelas modificações no funcionamento do mercado de trabalho. Na maior parte referem-se ao movimento conjuntural das economias, porém destaca-se, por seu impacto de ordem estrutural, a emergência do trabalho imaterial. Certamente, as alterações mais substanciais dizem mais respeito às economias urbano-industriais maduras em transição para as chamadas sociedades pós-industriais do que países agrários ou de industrialização tardia.

Em síntese, o caso das nações que conseguem elevar a expectativa média de vida da população acompanhadas da exigência de maior competência laboral e da demanda para que a educação siga, cada vez mais, a marcha da formação para a vida toda, o que rompe com a lógica do século 20 de somente haver ensino para as fases mais precoces do ciclo da vida humana. Adiciona-se a isso, o avanço da sociedade pós-industrial demarcado, sobretudo pela geração fundamental de postos de trabalho no setor terciário das economias (trabalho imaterial), cuja natureza formativa diverge acentuadamente da passada inserção e trajetória laboral contínua no interior das atividades primárias e secundárias da produção (trabalho material).

Diante do aparecimento de novas formas de organização da produção de bens e serviços nota-se a extensão do trabalho para além do exclusivo local de sua realização. Isto é, a possibilidade do exercício crescente do trabalho imaterial em qualquer local, sobretudo com o uso de novas tecnologias de comunicação e informação que tornam o ser humano quase que plugado 24 horas por dia no trabalho heterônomo. Não obstante o avanço tecnológico gerador de ganhos importantes de produtividade material e imaterial na sociedade pós-industrial, aumenta a pressão por mais tempo de trabalho. O paradoxo contemporâneo passa a ser entre a possibilidade da menor dimensão do tempo de trabalho heterônomo e o avanço das novas doenças do trabalho geradas pela profunda intensificação do trabalho nos tradicionais locais de emprego da mão de obra e pela ampliação da longevidade do trabalho em outras localidades (em casa ou em espaços públicos) permitidas por inovações tecnológicas e organizacionais.

Em função disso, a presente contribuição analítica entende que a emergência das novas formas de trabalho encontra-se conectada com a perspectiva geral de alteração na estrutura básica da formação educacional tanto para a o ciclo da vida humana como para a inserção e trajetória laboral. Isso parece ser a expectativa mais ampla que se pode captar dos principais atores envolvidos com a formação e as novas trajetórias no mundo do trabalho contemporâneo. 
O presente artigo encontra-se divido em três partes principais. A primeira trata dos aspectos vinculados nos momentos de transição dos sistemas de formação para o trabalho da sociedade agrária para a sociedade urbanoindustrial e desta para a sociedade pós-industrial. A segunda parte refere-se aos principais determinantes das transformações mais recentes nos sistemas de formação profissional. Nesse sentido, tem-se como referência, por exemplo, o envelhecimento da população, a postergação no ingresso no mercado de trabalho, as oscilações nas trajetórias ocupacionais, as alterações nas competências laborais, entre outras.

A terceira parte, por fim, discute as vias de construção do sistema de formação profissional compatíveis com as exigências e perspectivas dos atores sociais. Para o Estado, empresas e trabalhadores, a formação profissional alcança crescente centralidade diante da conformação de nova divisão da produção e, por conseqüência, do trabalho no mundo.

\section{Trajetória do Sistema de Formação para o Trabalho}

As principais transformações históricas no processo de formação para o trabalho humano encontram-se associadas às formas com que as sociedades conseguiram se organizar para a geração e distribuição da riqueza. O mundo que emerge neste começo do século 21 apresenta-se mais produtivo e com geração de riqueza em escala bem acima das necessidades de atendimento humano global, recolocando novamente a oportunidade impar de construção de uma sociedade em patamar superior, sobretudo nas economias avançadas.

De maneira geral, a evolução das sociedades tem permitido ao homem libertar-se gradualmente do trabalho vinculado tão somente à estrita necessidade de sobreviver ${ }^{2}$. Nas sociedades agrárias, por exemplo, o trabalho voltava-se fundamentalmente para o estrito objetivo de prover a sobrevivência, exigindo que o seu exercício ocorresse desde a fase infantil até o envelhecimento terminal.

Assim, a população encontrava-se prisioneira do trabalho pela sobrevivência, quando a expectativa média de vida estava ainda abaixo dos 40 anos de idade e a jornada de trabalho consumia $3 / 4$ do tempo de vida. Nessas sociedades, o trabalho pela sobrevivência era realizado justamente no próprio local de moradia. Morava-se no meio rural, trabalhava-se no meio rural, sendo a formação para o trabalho vinculado desde os 5 a 6 anos de idade à imitação da atitude e sociabilidade dos mais velhos.

A transmissão da tecnologia e dos modos de trabalho pertencia à tradição de longo prazo de valorização dos mais velhos, que tinham como missão apoiar a continuidade das atividades laborais no longo prazo no interior das próprias famílias $^{3}$. As escolas eram quase inexistentes, tornando a formação um evento de repasse do conhecimento existente pela simples prática e cultura oral.

Noutras palavras, o processo de formação para o trabalho ocorria simultaneamente ao exercício do próprio trabalho. Não havia inatividade para a 
aprendizagem, sem separação nítida entre tempo de trabalho e de não trabalho para formação. Exemplo disso eram os processos de transição formativa para o trabalho durante a Idade Média por meio das antigas guildas ou da aprendizagem de longa duração no interior das corporações de ofício.

A partir do século 19, com a transição para a sociedade urbana e industrial, surgem novas modalidades emancipatórias para a condição de trabalho fundado quase que na exclusiva luta pela sobrevivência. Os avanços transcorreram por meio da possibilidade de parcela da população (crianças, adolescentes, deficientes físicos e mentais, doentes e idosos) viver sem mais estar sujeita à condenação ao trabalho para o estrito custeio da sobrevivência, bem como pela redução da carga horária de trabalho aos segmentos sociais ativos (de 4 para 2 mil horas de trabalho ao ano) e elevação da proteção social aos riscos do trabalho penoso.

Esses avanços somente ocorreram com a construção de fundos públicos capazes de viabilizar o financiamento da inatividade de crianças, adolescentes e idosos, por meio de uma garantia generalizada de serviços (saúde, transporte e educação públicas), bens (alimentação, saneamento e moradia) e rendas (bolsas e subsídios). Assim, em conformidade com a expansão da base material da economia tornou-se possível elevar o padrão de bem-estar social associado ao imprescindível processo de lutas sociais e a instituições políticas protagonistas do novo padrão civilizatório.

Em função disso, o processo de formação para o trabalho se tornou organizado em grandes estruturas institucionais que passaram a atuar sob a inatividade que atingiu a fase precoce do ciclo de vida. Ou seja, o ingresso no mundo do trabalho postergado para após a finalização do processo educacional e formativo de crianças, adolescentes e jovens, geralmente financiado com recursos públicos e familiares.

Uma vez concluído o circuito inicial da formação, o ingresso no mundo do trabalho seria percorrido por trajetórias ocupacionais que duravam entre 25 e 35 anos do tempo de vida para novamente ser substituído pelo retorno à inativa remunerada por aposentadorias e pensões. Em geral, durante a vida adulta, após a conclusão do processo de educação básica, o contato com a formação não era recorrente, muitas vezes associado fundamentalmente ao segmento interno das grandes empresas que operavam por meio de plano de cargos e salários e formação corporativa.

Do ponto de vista da formação profissional ofertada por instituições públicas, geralmente associadas ao sistema público de emprego (seguro-desemprego, intermediação de mão de obra e qualificação), a sistemática procurava atender tanto problemas de curto prazo (desemprego conjuntural) como de longa duração (desemprego estrutural). Assim, o processo de formação tendia a focar, sobretudo, o ingresso no mercado de trabalho, ainda que não desconsiderasse as possíveis interrupções na trajetória laboral imposta pela condição do desemprego.

A partir do final do século 20, nota-se que a emergência da sociedade pósindustrial torna-se compatível com o surgimento de novas formas de valori- 
zação do trabalho humano para além da obrigação estrita pela sobrevivência ${ }^{4}$. A crescente postergação do ingresso dos jovens no mercado de trabalho e a maior redução no tempo do trabalho dos adultos, em combinação com a ênfase no ciclo educacional ao longo da vida, representam novas possibilidades para o trabalho no mundo, especialmente quando a expectativa de vida pode se aproximar dos 100 anos de idade.

Tudo isso, contudo, encontra-se inserido no contexto mais amplo das transformações tecnológicas e econômicas oriundas da profunda reorganização da produção ao longo das três últimas décadas. O melhor entendimento a respeito das metamorfoses na sociedade pós-industrial permite identificar os novos determinantes da formação para o trabalho neste começo do século 21.

\section{Desafio da Formação para o Trabalho Imaterial}

O processo de trabalho vigente durante o auge da economia urbano-industrial passou a sofrer profundas alterações no último quartel do século 20, com a constituição de novos e diferenciados espaços mundiais de acumulação do capital. Concomitante, assiste-se ao avanço de uma nova Divisão Internacional do Trabalho, que se fundamenta cada vez mais na separação entre a concepção e a execução laboral no interior do conjunto das atividades econômicas. Tratase fundamentalmente da emergência do trabalho imaterial ${ }^{5}$.

Diferentemente do que prevaleceu ao longo do século 20, a atual Divisão Internacional do Trabalho tende a abandonar a tradicional separação setorial entre o trabalho agrário e o industrial. A adoção de novas estratégias de competitividade e de produtividade representada por uma nova conduta empresarial seria uma das principais razões explicativas para as intensas mudanças na organização do trabalho.

Na maior parte das vezes, as alterações vêm produzindo sinais que resultam na combinação entre inovações e retrocessos no âmbito das relações de trabalho, tendo em vista que o movimento maior de reestruturação das empresas se fundamenta tanto na economia do conhecimento como na economia da financeirização da riqueza ${ }^{6}$. Entre os segmentos que compõem o curso da reestruturação capitalista, encontram-se, entre outros, os segmentos de informação e comunicação e os da biotecnologia, responsáveis pelo aparecimento de novas relações entre o trabalho manual e o intelectual.

Para além da tradicional Divisão Internacional do Trabalho que demarcou todo o século 20, por meio da setorização do trabalho urbano-industrial e agropecuário, percebem-se avanços significativos nas atividades laborais centradas na concepção ou na execução em marcha na geoeconomia mundial do emprego da mão de obra. Mas isso, contudo, não vem se manifestando sem a plena subsunção do trabalho não material, com a evolução da intelectualização nos procedimentos de trabalho nos setores industriais e de serviços, bem como na generalização do consumo? . 
De certa forma, prevalece um conjunto de intensas disputas empresariais seguidas pela apropriação do conhecimento e da tecnologia, o que contribui para a constituição de um novo paradigma organizacional do trabalho, muito distinto do que prevaleceu durante o auge da economia industrial no século passado. Mesmo que o padrão fordista-taylorista de organização do trabalho urbano-industrial venha sendo reprogramado, com as modificações introduzidas por uma série de novidades processuais no âmbito da produção flexível (toytismo, just in time), permanecem ainda os sinais de sua incapacidade plena no atendimento de um conjunto de determinações imposto pelos diferenciados e inovadores espaços de acumulação capital.

Talvez por isso, as renovadas configurações no interior do antigo padrão fordista-taylorista, como as redes de produção e redistribuição no espaço mundial, terminam por combinar tanto o novo como o velho nas relações de trabalho. Em outras palavras, situações de produção portadoras de novas condições e relações de trabalho coexistem com retrocessos nas atividades laborais próximas das do século 19.

Assim, em meio à expansão generalizada do padrão de trabalho asiático (flexível com extensa jornada, baixo salário e elevada rotatividade), agrupamse algumas referências localizadas de avanços nas condições e relações de trabalho condizentes com as expectativas do século 21 (reduzida jornada, alta remuneração e estabilidade ocupacional). Por não se constituir na sua totalidade, o novo padrão de trabalho tende a reproduzir algumas similitudes já percebidas no antigo processo laboral, como a organização das atividades de escritório e de prestação de serviços vinculadas às atividades de produção (assalariado e autônomo), com a repetição racionalizada e em grandes escalas para o exercício de tarefas fracionadas e controladas por tempo (taylorista), geralmente comprometidas com ganhos crescentes de produtividade (fordista) ${ }^{\text {. }}$.

No interior do padrão de produção fordista justificou-se a separação entre o trabalho intelectual, caracterizado por cargos de direção e supervisão dispersos nas atividades de administração e supervisão, e o trabalho manual representado pelo conjunto de empregados alocados no chão da fábrica para execução de uma série de atividades simplificadas por repetição e rotina9. Desta forma, a subsunção do trabalho no âmbito do processo produtivo urbano-industrial passou a generalizar-se desde o século 19 , quando os trabalhadores do artesanato e de ofício foram perdendo a capacidade de continuar monopolizando as técnicas de produção, antigamente concentrada nas corporações de ofício que predominaram até a Idade Média (guildas) ${ }^{10}$.

Até então, a finalidade principal do sistema corporativo era a preservação do controle do processo de trabalho por mestres-artesãos, cuja reprodução do saber produtivo era quase monopólio das antigas escolas de artes e ofícios. Mas, combinado com a introdução da mecanização no interior da produção, emergiu um conjunto de novas técnicas de ordenamento das atividades laborais que permitiu a difusão de novos processos de trabalho no capitalismo industrial do século 19 , muitas vezes de menor qualificação que as atividades de ofício. 
De um lado, o avanço da mecanização foi retirando simultaneamente a autonomia do trabalho humano, tornando o empregado uma espécie de apêndice da máquina, que estabelecia os próprios ritmo e organização do trabalho. De outro, as novas técnicas sistêmicas de gerenciamento da mão de obra, originalmente capturadas dos antigos segredos de ofício, passaram a permitir a simplificação do trabalho, por meio do fracionamento, repetição e rotinização das atividades laborais ${ }^{11}$.

Assim, o estabelecimento dos princípios da chamada organização científica do trabalho ganhou maior dimensão com a estruturação do padrão industrial da grande empresa. Mas somente com a Grande Depressão de 1929 o processo de trabalho taylorista (simplificação, fragmentação, repetição e rotinização) foi associado ao paradigma fordista de produção e consumo em grande escala de serviços e bens manufaturados.

Em síntese, a subsunção do trabalho foi determinada por condições técnicas que alteraram profundamente o processo de trabalho. Na Primeira Revolução Industrial (1750-1820), com a introdução da máquina-ferramenta, o conhecimento do trabalho artesanal foi absorvido pela manufatura, permitindo o crescimento extraordinário da produtividade do trabalho.

O processo de trabalho individual e autônomo do artesão qualificado transitou para o processo de trabalho coletivo desqualificado do empregado subordinado ao ritmo da produção estabelecido pela máquina. Com o avanço da industrialização, esse novo processo de trabalho foi sendo generalizado internacionalmente, inclusive em algumas nações periféricas ao longo do século $20^{12}$.

Mas, com os sinais de esgotamento do padrão fordista de produção e consumo em massa a partir da década de 1970, não apenas o circuito da produção de bens e serviços sofreu alterações profundas, como se modificaram os processos tradicionais de trabalho. No âmbito das atividades de serviços, que ganham predominância na estrutura produtiva, o processo de trabalho tende a se manifestar distintamente daquele vigente na produção urbano-industrial.

Em primeiro lugar, porque o segmento de serviços compreende um amplo conjunto heterogêneo de atividades, embora metodologicamente classificado ainda hoje como um só. Assim, por exemplo, o transporte, a logística, a hospedagem, o ensino, a comunicação, o comércio, as finanças, a administração pública, entre outros, fazem parte do amplo setor terciário das atividades econômicas, já que eram justamente aquelas atividades que restavam da tradicional divisão entre os setores primário (agricultura, pecuária, extrativismo) e secundário (indústria, construção civil) ${ }^{13}$.

Em segundo lugar porque a categoria de trabalhadores alocada no setor de serviços abrange uma enorme diversidade de formas de contratação laboral nos segmentos estruturados, que incluía as atividades assalariadas de gerências e supervisão em escritórios, de conta própria e autônoma, bem como estratégias simplificadas e brutalizadas de sobrevivência (subemprego e informalidade). No geral, algumas ocupações se diferenciavam por ser reconhecidas como de classe média, justamente por não se situarem no chão de fábrica e não permiti- 
rem a formação de estoques decorrentes da simultaneidade dos procedimentos de produção e consumo e do uso ilimitado de máquinas que substituíssem o trabalho humano ${ }^{14}$.

O setor de serviços tem por características adicionais a absorção de parcela da força de trabalho excedente dos setores primários e secundários da economia, geralmente em ocupações precárias. Por meio do segmento informal, a organização do trabalho abriga nos serviços diversas estratégias humanas de sobrevivência, podendo chegar a atender, inclusive, o consumo final dos segmentos de alta renda e de setores empresariais nas formas de atividades serviçais ou até no interior das cadeias produtivas ${ }^{15}$.

Mais recentemente, com a busca de novos espaços de acumulação de capital frente à crise do padrão taylorista-fordista de produção e consumo, o processo de trabalho vem sofrendo profundas e intensas modificações. Ocorre, de um lado, o enorme excedente de mão de obra e, de outro, o desenvolvimento das tecnologias de informação e comunicação em redes organizacionais associadas aos diversos espaços territoriais no planeta, com processos de trabalho cada vez mais caracterizados pela subcontratação da mão de obra ${ }^{16}$.

Com isso, os ganhos de produtividade se tornaram ascendentes, embora de difícil mensuração pelos tradicionais cálculos que relacionam avanços na produção física com hora efetivamente trabalhada ou quantidade de trabalhadores. Por ser cada vez mais direta, relacional e informacional, e ainda demarcado por relações de tipo produtor e consumidor, o trabalho de natureza imaterial vai permitindo avançar o auto-serviço e fundamentalmente a terceirização $0^{17}$.

\section{Novos Entendimentos para a Formação do Trabalho}

Desde o último quartel do século 20 que se encontra em curso inéditos requisitos da formação de um novo trabalhador, mais condizente com as alterações no conteúdo e nas condições de produção e gestão em rede por empresas cada vez mais internacionalizadas. Por conta de possível inadequação entre demanda de trabalho mais exigente e oferta de trabalhadores com menor preparação, os requisitos de qualificação profissional e elevação das habilidades para o exercício laboral tornaram-se crescentes, cada vez mais distantes das tradicionais sistemas de educação e formação profissionais herdados da sociedade urbano-industrial.

Ao contrário do analfabetismo tradicionalmente identificado nos séculos XIX e XX pelo desconhecimento pleno da língua de origem, ganha destaque atualmente o analfabetismo funcional imposto pela mudança técnica e informacional. Em geral, as perspectivas dos estudos realizados tendem a fazer maior referência às possibilidades de expansão das ocupações profissionais que utilizam maior informação e nas atividades multifuncionais, sobretudo naquelas sustentadas por exigências crescentes de maior escolaridade e qualificação profissional ${ }^{18}$. 
Nesse sentido, os perfis ocupacionais tendem a se relacionar com a crescente capacitação tecnológica. Mas o cenário em construção para o mundo do trabalho parece refletir mais as mutações marcadas pela maior insegurança e competição, resultando na ampliação do analfabetismo funcional ${ }^{19}$. Novos conhecimentos científicos e tecnológicos encontram-se associados às exigências empresariais de contratação de empregados com polivalência multifuncional, maior capacidade motivadora e ampliadas habilidades laborais no exercício do trabalho. Esses requisitos profissionais, indispensáveis ao ingresso e à permanência no interior do mercado de trabalho em transformação, seriam passíveis de atendimento somente por meio de um maior nível educacional de qualidade dos trabalhadores.

Mas isso, por si só, não corresponde, necessariamente, à garantia de elevação do nível nacional de ocupações, nem mesmo a melhor qualidade no uso e remuneração da força de trabalho. Em síntese, cabe destacar, para além da forma de inserção na Divisão Internacional do Trabalho, o papel que possui a estrutura produtiva na determinação interna do nível geral de ocupação.

Em síntese, a estrutura ocupacional das economias capitalistas vem, em maior ou menor medida, seguindo as tendências de longa duração de transição do trabalho primário (agropecuário) passando do trabalho manufaturado até atingir o trabalho no setor terciário. Desde a década de 1950 que o setor industrial vem perdendo participação relativa no total da ocupação.

Com o movimento de redução relativa do emprego no setor industrial, ganha cada vez mais destaque o setor terciário na ocupação da maior parcela de trabalhadores, uma vez que o setor primário vem reduzindo a sua participação relativa no total da ocupação. A expansão do setor terciário tem sido intensa, nem sempre suficiente para compensar a queda na participação relativa das ocupações nos setores industrial e agropecuário, embora em ritmo inferior ao da expansão da força de trabalho, o que significa a presença de alto desemprego da mão de obra.

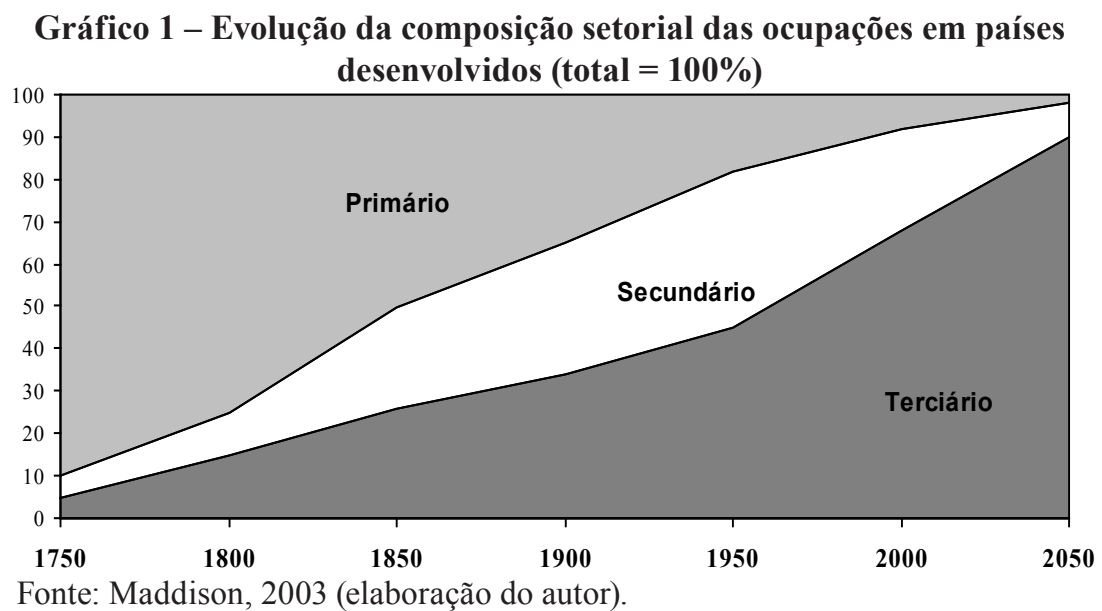


É neste contexto que a reorganização em curso do trabalho material e imaterial pressupõe uma profunda reflexão a respeito da formação profissional ao longo do século 21. Com os avanços da nova economia da tecnologia, os sistemas de formação educacional e formativos para o exercício do trabalho heterônomo herdados da sociedade urbano-industrial tornam-se cada vez mais antiquados ${ }^{20}$.

Mesmo porque a transição do trabalho da sociedade urbano-industrial para a sociedade pós-industrial abre a perspectiva de maior redução do tempo de trabalho comprometido com o trabalho heterônomo. De certa forma, o tempo livre deve constituir-se mais como componente alternativo do exercício do trabalho heterônomo, contribuído para alimentar novas formas das riquezas imateriais como lazer, ócio, criatividade, entretenimento, comunitário, entre outras $^{21}$.

Do contrário, a intensificação e ampliação do tempo de trabalho heterônomo tendem a fazer valer o universo das doenças profissionais frente ao agravamento das condições de coesão social. De maneira geral, o ciclo de novas doenças laborais difere significativamente do anterior, cada vez mais associado ao esforço repetitivo e a degeneração intelectual ${ }^{22}$.

Nos dias de hoje, a condição de trabalho pressupõe alteração profunda com o ciclo de vida e de estudo. Ao longo da vida moderna, as condições tradicionais de coesão social encontram-se fraturadas, com padrão familiar fortemente superado pela dos arranjos monoparentais. A sociabilidade mecânica precisa ser ampliada por novas bases mais humanas e fraternas.

$\mathrm{Na}$ sociedade pós-industrial, o conhecimento torna-se estratégico na inserção e configuração das novas trajetórias ocupacionais portadoras de maior articulação da vida com o estudo e trabalho ${ }^{23}$. Sobre o resgate da formação profissional não cabe partir da mera reprodução do passado, mas de sua reinvenção nos termos necessários à reorganização da vida e trabalho em plano superior ao atualmente existente.

Com isso, a educação deixa de ser algo centrado nas fases precoces da vida (crianças, adolescente, jovens e alguns poucos adultos), como no passado, para ser algo necessário ao longo da vida. Ao invés da separação do tempo de inatividade com o tempo de trabalho presente na sociedade urbano-industrial, chega-se cada vez mais à transição do tempo da inatividade com a atividade pelo trabalho imanente do conhecimento.

Para haver educação para o ciclo completo da vida (infância, adulto e velhice), cuja expectativa aproxima-se dos 100 anos de idade, os sistemas de formação profissional precisam incorporar cada vez mais os pressupostos do diálogo desenvolvido pelo conjunto dos atores sociais ${ }^{24}$. Novas formas de produção e de reorganização do trabalho não existem sustentavelmente sem uma base recorrente de educação e formação profissional.

$\mathrm{O}$ resgate da educação e da formação profissional deve compreender o saber como elemento central do rearranjo básico entre os atores sociais, como a postergação do ingresso no mercado de trabalho e a conexão alongada com 
os segmentos populacionais envelhecidos ${ }^{25}$. Sem isso, o processo de metamorfose no trabalho tende a obstaculizar as possibilidades de universalização das oportunidades das sociedades fundadas no conhecimento ${ }^{26}$.

O diálogo social pode representar o caminho mais rápido e inadiável do fortalecimento da educação e da formação profissional contemporânea aos desafios do começo do século 21. A negociação coletiva de trabalho permite estabelecer as bases da formação no plano mais local do processo produtivo, enquanto no plano mais geral cabem as instituições democráticas de expressão do conjunto dos distintos interesses da sociedade a promoção da trajetória formativa, conforme algumas experiências nacionais e locais permitem ser observadas até o momento ${ }^{27}$.

$\mathrm{Na}$ transição dos sistemas de formação para o trabalho da sociedade urbano-industrial para a pós-industrial, o entendimento entre os atores sociais relevantes pressupõe condição necessária para a maior eficiência alocativa dos meios de produção. Da mesma forma, reveste-se da possibilidade de compartilhar os novos ganhos de produtividade com patamar de civilidade superior ao do século 20 .

\section{Considerações Finais}

$\mathrm{Na}$ transição atual da sociedade urbano-industrial para a pós-industrial, percebe-se o acúmulo de novas e importantes perspectivas acerca do trabalho, conforme se procurou destacar. Uma via dessas novidades encontra-se relacionada à perspectiva de ampliação da expectativa média de vida, especialmente nas economias avançadas. Há mais de cem anos, ainda durante o predomínio da sociedade agrária, a esperança de vida ao nascer não superava, por exemplo, os 40 anos de idade. Ao longo do século XX, com o apogeu da sociedade industrial, a longevidade humana quase dobrou para os 70 anos de idade, em média. Na sociedade pós-industrial, os mais de 100 anos de esperança de vida ao nascer não mais parecem distantes.

A partir disso, adicionam-se ainda mais três significativas novidades possíveis para a perspectiva do trabalho e de seu processo formativo. Uma primeira relaciona o comprometimento do trabalho com o ciclo da vida humana. $\mathrm{Na}$ sociedade agrária, o trabalho começava a ser exercido a partir dos 5 a 6 anos de idade para se prolongar até praticamente a morte, com jornadas de trabalho extremamente longas (14 a 16 horas por dia) e sem períodos de descanso, como férias e inatividade remunerada (aposentadorias e pensões). Para alguém que conseguisse chegar aos 40 anos de idade tendo iniciado o trabalho aos 6 anos, por exemplo, o tempo comprometido somente com as atividades laborais absorvia cerca de $70 \%$ de toda a vida humana. Naquela época, em síntese, viver era fundamentalmente trabalhar, já que praticamente não havia uma separação nítida entre tempo de trabalho e de não trabalho.

Na sociedade industrial, o ingresso no mercado laboral foi postergado para 16 anos de idade, garantindo aos ocupados, a partir daí, o acesso ao descanso 
semanal, férias, pensões e aposentadorias provenientes da regulação pública do trabalho. Com isso, alguém que ingressasse no mercado de trabalho depois dos 15 anos de idade e permanecesse ativo por mais 50 anos, teria, possivelmente, mais alguns anos de inatividade remunerada (aposentadoria e pensão).

Por força disso tudo, sabe-se que menos de $50 \%$ do tempo de toda a vida estaria comprometida com o exercício do trabalho heterônomo. Nesse sentido, o ciclo da vida teria abandonado a condição de representar somente o trabalho heterônomo, tendo o tempo de trabalho abandonado a rigidez tradicional da separação com o tempo de não trabalho (inatividade laboral).

No curso da nova sociedade pós-industrial, a inserção no mercado de trabalho encontra-se gradualmente sendo postergada ainda mais, possivelmente para o ingresso na atividade laboral para somente após a conclusão do ensino superior, com idade acima dos 24 anos de idade, e saída sincronizada do mercado de trabalho a partir dos 70 anos. Tudo isso acompanhado por jornada de trabalho reduzida, o que permite observar que o trabalho heterônomo deva corresponder a não mais do que $25 \%$ do tempo da vida humana.

A parte restante do ciclo da vida, contudo, dificilmente tende a se constituir, necessariamente, em tempo livre, devido aos deslocamentos territoriais e aos compromissos de sociabilidade, estudo e formação cada vez mais exigidos pela nova organização da produção e distribuição internacionalizada. Isso porque, frente aos elevados e constantes ganhos de produtividade, torna-se possível a redução do tempo semanal de trabalho de algo ao redor das 40 horas para não mais de 20 horas. De certa forma, a transição entre as sociedades urbanoindustrial e pós-industrial tende a não mais separar nítida e rigidamente o tempo do trabalho do não trabalho. Nesse sentido, há uma possibilidade não desprezível de maior mescla entre os dois tempos de trabalho e não trabalho, impondo maior intensidade e o risco da longevidade ampliada da jornada laboral para além do tradicional local de exercício efetivo do trabalho.

Destacam-se das novas tecnologias (internet e telefonia celular) em contato com as inovações na gestão da mão de obra não apenas a intensificação do exercício no próprio local de trabalho. Adiciona-se a isso, a extensão do trabalho exercido cada vez mais para além do local de trabalho, sem contrapartida remuneratória e protetiva, posto que os sistemas de regulação pública do trabalho encontram-se fundamentalmente focados na empresa.

Outra importante novidade que necessita ser considerada resulta da forte concentração do trabalho no setor terciário das economias (serviços em geral), podendo representar cerca de $90 \%$ do total das ocupações. Assim, o terciário tende não apenas a assumir uma posição predominante, tal como representou a alocação do trabalho no setor agropecuário até o século XIX, com a indústria respondendo por não mais de $10 \%$ do emprego total, como passar a exigir, por conseqüência, novas formas de organização e de representação dos interesses num mundo do trabalho mais heterogêneo. Nos países desenvolvidos, por exemplo, os setores industriais e agropecuários absorvem atualmente não mais do que $10 \%$ do total dos ocupados. 
Por fim, cabe ainda, observar outra novidade importante que deriva da profunda alteração que emerge entre a relação da educação com o trabalho e a vida. Até o século 19, por exemplo, o ensino era quase uma exclusividade da elite econômica e política em cada país.

No século 20, contudo, o acesso à educação gradualmente generalizou-se, alcançando parcelas crescentes do conjunto da sociedade urbano-industrial, com a universalização do aceso às faixas etárias mais precoces se transformando num dos requisitos de sociabilidade e preparação para o exercício do trabalho. Na sociedade pós-industrial, a educação tende a acompanhar mais continuamente o longo ciclo da vida humana, não somente como elemento de ingresso e continuidade no exercício do trabalho heterônomo, mas também enquanto condição necessária para a cidadania ampliada por toda a vida.

Conectar a totalidade das transformações do mundo do trabalho com o resgate da educação e a formação profissional em novas bases passa pela redivisão da riqueza entre o fundo público - único que pode sustentar as novidades do trabalho na sociedade pós-industrial - e o capital virtual (trabalho imaterial), capaz de revolucionar a titularidade da riqueza no futuro. Dessa forma, os ganhos de produtividade (material e imaterial) poderão ser capturados significativamente a tal ponto de superar mais rapidamente a anacrônica separação entre o trabalho pela sobrevivência (trabalho heterônomo) o trabalho autônomo (criativo, comunitário).

Noutras palavras, o trabalho heterônomo para parcelas ativas da sociedade tende a ser mais contido, o que torna crescentes as possibilidades do trabalho autônomo. Para isso, contudo, as nações portadoras de futuro e geradoras dos postos de trabalho de concepção, com maior qualidade e remuneração, pressupõem maior capacidade de ampliação dos investimentos em tecnologia na produção de bens e serviços com maior valor agregado possível.

Do contrário, há o risco de retrocessos na redivisão do trabalho entre países, com parcela deles comprometidos fundamentalmente com a produção de menor custo de bens e serviços geralmente associada ao reduzido conteúdo tecnológico e valor agregado e dependente do uso de trabalho precário e de execução em longas jornadas sub-remuneradas. Ou seja, a reprodução do passado, com elevadas jornadas de trabalho, reduzida remuneração e forte instabilidade contratual, sem a possibilidade de fazer valer a transição dos sistemas de educação e formação contemporâneos da sociedade pós-industrial.

Essa situação já é real em vários países. No novo mundo do trabalho repleto de novidades, as escolhas nacionais estão sendo feitas. O retorno dos investimentos na formação profissional para a inserção e trajetória profissional de novo tipo faz parte da superação mais rápida dos atrasos contidos nas sociais. As decisões de políticas públicas de hoje podem asfaltar, inexoravelmente, o caminho técnico do amanhã em bases superiores.

Recebido em março de 2012 e aprovado em maio de 2012. 


\section{Notas}

1 A editoria agradece à Prof ${ }^{a}$. Naira Lisboa Franzoi a elaboração do resumo deste artigo.

2 Para maiores detalhes, consultar: Gorz, 2003; Mészários, 2007; Rosso 2008; ThiryCherques, 2004; Pochmann, 2009; Masi, 1999; Hobsbawn, 1981; Neffa, 2003.

3 Sobre isso ver mais em: Naldini; Saraceno, 2003; Burguière et al., 1999; Roudinesco, 2003; Peixoto, 2004; Therborn, 2006.

4 Ver mais em: Colbari, 1995; Pochmann, 2008; James et al., 1997; Toledo; Neffa, 2001; Boissonnat, 1998; Méda, 1998; Antunes, 1999; Rosso, 1996; Rifkin, 1995.

5 Mais informações em: Demain, 2009; Alves, 2011; Amorim, 2009; Gorz, 2009.

6 Para maiores detalhes, ver: Foray, 2000; Braga, 1993; Chesnais, 1996.

7 Sobre isso, ver mais em: Pochmann, 2001; Bolaño, 2002.

8 Destaque para: Harvey, 1992; Soares, 1992.

9 Ver mais em: Pires, 1998; Antunes, 2006.

10 Para maiores detalhes, ver: Burawoy, 1990; Braverman, 1981.

11 Ver mais em: Taylor, 1970; Banham, 1979; Coriat, 1982.

12 Mais informações em: Dunlop, 1985; Bamber; Lansbury, 1998.

13 Sobre isso, ver: Kon, 2004; Mills, 1979.

14 Ver mais em: Offe, 1991; Mello et al., 1998.

15 Detalhes em: Cacciamali, 1987; Souza, 1980.

16 Sobre isso, ver: Offe, 1995; Castel, 1998; Castells, 1996; Crompton et al., 1996.

17 Detalhes em: Soares, 1999; Mello et al., 1998; Negri; Lazzarato, 2001.

18 Para maiores detalhes, consultar: Santos, 2005; Reich, 1993; Reilly; Lojeski, 2009.

19 Sobre isso, ver: Viar, 2006; Franco; Druck, 2007; Sennet, 1999; Braga, 1997.

20 Ver mais em: Amaral, 2008; Lojkine, 1995; Plihon, 2003; Alonso, 1999.

21 Mais detalhes em: Santos; Gama, 2008; Grazia, 1966; Dumazedier, 1994; Lafargue, 2003; Weneck, 2000.

22 Mais detalhes em: Dejours, 2003a, 2003b; Mendes et al., 2002; Jacques; Codo, 2003; Codo, 1999.

23 Sobre a relação do padrão de coesão social e organização da vida com o trabalho ver: Mauss, 1999; Offe, 1989; Masi, 1999.

24 Para mais informação, consultar: Jacinto, 2004; Oliveira, 2006; Green; Ashton, 1996; Leite, 1996; Jovier, 1991; Moro, 1998; Aranha, 1999; Peirone, 1995.

25 Detalhes com: Camarano, 2006; Schirrmacher, 2005; INSEE, 1996; Laville, 1993.

26 Ver, por exemplo: Diniz, 2001, Requena, 1991; Harman; Hormann, 1990; Kavács, 2002.

27 Ver: Uriarte; Rímol, 1998; Casanova, 2004; Fluitman, 1989; Bindé, 2008. 


\section{Referências}

ALONSO, Luis Enrique. Trabajo y Ciudadania. Madrid: Editorial Trotta, 1999.

ALVES, Giovanni. Trabalho e Subjetividade. O Espírito do Toyotismo na Era do Capitalismo Manipulatório. São Paulo: Boitempo, 2011.

AMARAL, Luis Mira. Economia Tech - da Indústria À Sociedade da Informação e do Conhecimento. Lisboa: Booknomics, 2008.

AMORIM, Henrique. Trabalho Imaterial: Marx e o debate contemporâneo. São Paulo: Annablume, 2009.

ANTUNES, Ricardo. Os Sentidos do Trabalho. Ensaio sobre a Afirmação e a Negação do Trabalho. 4. ed. São Paulo: Boitempo, 2001.

ARANHA, Lucia. Educação e Trabalho no Contexto da Terceira Revolução Industrial. São Cristóvão: UFS, 1999.

ASHTON, David; GREEN, Francis. Education, Training and the Global Economy. Cheltenham: E. Elgar, 1996.

BINDÉ, Jerome. Rumo Às Sociedades do Conhecimento. Lisboa: I. Piaget, 2007.

BOISSONNAT, Jean-Daniel. Horizontes do Trabalho e do Emprego. São Paulo: LTr, 1995.

BOURGUiÈRE, André et al. (Org.). História da Família. Lisboa: Terramar, 1999.

BRAGA, Ruy. A Restauração do Capital - Um Estudo sobre a Crise Contemporânea. São Paulo: Xamã, 1997.

CAMARANO, Ana Amélia (Org.). Transição para a Vida Adulta ou a Vida Adulta em Transição. Brasília: IPEA, 2006.

CASANOVA, Fernando. Desarrollo Local, Tejidos Productivos y Formación. Montevideo: Cinterfor/OIT, 2004.

CASTEL, Robert. As Metamorfoses da Questão Social. Petrópolis: Vozes, 1998.

CODO, Wanderley. Educação: carinho e trabalho. Petrópolis: Vozes, 1999.

COLBARI, Antonia de Lourdes. Ética do Trabalho. São Paulo:UFES, 1995.

DAL ROSSO, Sadi. A Jornada de Trabalho na Sociedade: o castigo de Prometeu. São Paulo: LTr, 1996.

DAL ROSSO, Sadi. Mais Trabalho! São Paulo: Boitempo, 2008.

DEJOURS, Christophe J. A Banalização da Injustiça Social. Rio de Janeiro: Editora FGV, 2003a, $5^{\text {a }}$ edição.

DEJOURS, Christophe J. A Loucura do Trabalho. 5. ed. São Paulo: Cortez Editora, 2003b.

DEMAIN, V. Bomsel Oliver. Économie Immatérielle. Paris: Dangles, 2009.

DINIZ, Marli. Os Donos do Saber. Rio de Janeiro: Revan, 2001.

DRUCK, Graça; FRANCO, Tania (Org.). A Perda da Razão Social do Trabalho. São Paulo: Boitempo, 2007.

DUMAZEDIER, Joffre. A Revolução Cultural do Tempo Livre. São Paulo: SESC, 1994.

FLUITMAN, Fred. Training for Work in the Informal Sector. Geneve: ILO, 1989. 
GORZ, Andre. Metamorfoses do Trabalho. São Paulo: Annablume, 2003.

GORZ, Andre. O Imaterial. São Paulo. Annablume, 2009.

GRAZIA, Sebastián de. Tiempo, Trabajo y Ocio. Madrid: Tecnos, 1966.

HOBSBAWM, Eric John Earnest. Os Trabalhadores. Estudos sobre a História do Operariado. Rio de Janeiro: Zahar, 1981.

HORMANN, Will; HARMAN, John. O Trabalho Criativo. São Paulo: Cultrix, 1990.

INSTITUT NATIONAL DE LA STATISTIQUE ET DES ÉTUDES ÉCONOMIQUES (INSEE). Entre l'Emploi et la Retraite. Paris: INSEE, 1996.

JACINTO, Claudia (Org.). Educar para que Trabajo? Buenos Aires: La Crujía, 2004. JACQUES, Maria da Graça; CODO, Wanderley (Org.). Saúde Mental \& Trabalho: leituras. 2. ed. Petrópolis: Vozes, 2003.

JAMES, Paul; Walter F. Veit; Steve Wright (Org.). Work of the Future. Sidney: Allen \& Unwin, 1997.

KON, Anita. Economia de Serviços: teoria e evolução no Brasil. Rio de Janeiro: Campus, 2004.

KOVÁCS, Ilona. As Metamorfoses do Emprego: ilusões e problemas da sociedade da informação. Oeiras: Celta, 2002.

LAFARGUE, Paul. O Direito à Preguiça. São Paulo: Editora Claridade, 2003.

LAVILLE, Antoine (Org.). Envejecimiento y Trabajo. Buenos Aires: CEIL/CONICET, 1993.

LAZZARATO, Maurizio; NEGRI, Antonio. Trabalho Imaterial. Rio de Janeiro: Dp\&A, 2001.

LEITE, Elenice Monteiro. El Resgate de La Calificación. Montevideo: Cinterfor/ OIT, 1996.

LOJESKI, Karen Sobel;REILLY, Richard R. Novas Relações de Laborais. Lisboa: Smartbook, 2009.

LOJKINE, Jean. A Revolução Informacional. 3. ed. São Paulo: Cortez, 1995.

MADDISON, Angus. The World Economy: historical statistics. Paris: OECD, 2003. MASI, Domenico de. A Sociedade Pós-Industrial. São Paulo: Senac, 1999.

MASI, Domenico de. O Futuro do Trabalho. Rio de Janeiro: José Olympio, 1999.

MAUSS, Marcel C. Ensaios de Sociologia. São Paulo: Perspectiva, 2005.

MÉDA, Dominique. El Trabajo. Barcelona: Gedisa, 1998.

MENDES, Ana Magnólia Bezerra; BORGES, Lívia de Oliveira; FERREIRA, Maria César (Org.). Trabalho em Transição, Saúde em Risco. Brasília: Editora Unb, 2002.

MÉSZÁROS, István. O Desafio e o Fardo do Tempo Histórico. São Paulo: Boitempo, 2007.

MORO, Giuseppe. La Formazione nelle Società Post-Industriali. Roma: Carocci, 1998.

NEFFA, Julio César; TOLEDO, Enrique de La Garza (Org.). EI Trabajo del Futuro, el Futuro del Trabajo. Buenos Aires: CLACSO, 2001.

NEFFA, Julio César. EI Trabajo Humano. Buenos Aires: Lumen, 2003. 
OFFE, Claus. Capitalismo Desorganizado: transformação do trabalho e da política. São Paulo: Brasiliense, 1989.

OFFE, Claus. Trabalho e Sociedade. Rio de Janeiro: Tempo Brasileiro, 1989.

OLIVEIRA, Roberto Verás de (Org.). Qualificar para quê? Qualificação para quem? Do Global ao Local: o que se espera da qualificação profissional hoje. Campina Grande: EDUFCG, 2006.

PEIRONE, Mariella. Educare nelle Diversitá. Torino: EIRAS, 1995.

PEIXOTO, Clarice Ehlers (Org.). Família e Envelhecimento. Rio de Janeiro: FGV, 2004.

PLIHON, Dominique. O Novo Capitalismo. Coimbra: CC, 2003.

POCHMANN, Márcio. O Emprego na Globalização. São Paulo: Boitempo, 2001.

POCHMANN, Márcio. Qual Desenvolvimento? São Paulo: Publisher, 2009.

POCHMANN, Márcio. Desenvolvimento e Perspectivas Novas para o Brasil. São Paulo: Cortez, 2010.

POCHMANN, Márcio. Novos e Velhos Tempos do Trabalho. In: OLIVEIRA, Roberto Véras de (Org.). Novo Momento para as Comissões de Emprego no Brasil? São Paulo: a + comunicação, 2007.

POCHMANN, Márcio. Transformações Contemporâneas no Emprego. In: DEDECCA, Claudio Salvadore; PRONI, Marcelo Weishaupt (Org.). Economia e Proteção Social: textos para estudo dirigido. Campinas: IE/UNICAMP, 2007.

REICH, Robert B. O Trabalho das Nações: preparando-nos para o capitalismo do século 21. São Paulo: Educator, 1995.

REQUENA, Jaime. Propiedad Intelectual y Desarrollo Tecnológico. São Paulo: Monte Avila Editores, 1991.

RIFKIN, Jeremy. The end of Work: the Decline of Global Labor Force and the Dawn Of the Post-Market Era. New York: Putnam, 1995.

ROUDINESCO, Elisabeth. A Família em Desordem. Rio de Janeiro: Zahar, 2003.

SANTOS, Boaventura de Sousa (Org.). Trabalhar o Mundo: os caminhos do novo internacionalismo operário. Rio de Janeiro: Civilização Brasileira, 2005.

SANTOS, Noberto Pinto dos; GAMA, António. Lazer. Da Libertação do Tempo à Conquista das Práticas. Coimbra: Imprensa UC, 2008.

SARACENO, Chiara; NALDINI, Manuela. Sociologia da Família. Lisboa: Estampa, 2003.

SCHIRRMACHER, Frank. A Revolução dos Idosos. Rio de Janeiro: Campus, 2005.

SENNETT, Richard. A Corrosão do Caráter. Rio de Janeiro: Record, 1999.

THERBORN, Göran. Sexo e Poder. São Paulo: Contexto Editora, 2006.

THIRY-CHERQUES, Hermano Roberto. Sobreviver ao Trabalho. Rio de Janeiro, FGV, 2004.

TORREGROSA DEMAIN, Daniel Jover. La Formación Ocupacional. Madrid: Editorial popular, 1991.

URIARTE, Oscar Ermida; RÍMOLO, Jorge Rosenbaum. Formacíon Profesional em La Negociación Colectiva. Montevideo: Cinterfor/OIT, 1998. 
VIARD, Jean. Éloge de la Mobilité. Gemenos: Láube, 2006.

WERNECK, Christianne Luce Gomes. Lazer, Trabalho e Educação: relações históricas, questões contemporâneas. Belo Horizonte: Editora UFMG, 2000.

Marcio Pochmann é professor licenciado do Instituto de Economia e do Centro de Estudos Sindicais e de Economia do Trabalho da Universidade Estadual de Campinas. Presidente do Instituto de Pesquisa Econômica Aplicada (IPEA), no período de 2007 a junho de 2012.

E-mail: pochmann@eco.unicamp.br 